\section{perifèria}

Número 18(2), diciembre 2013

http://revistes.uab.cat/periferia

\title{
La movilidad guna (Panamá): Habitando bosques, islas $y$ ciudades
}

\author{
Mònica Martínez Mauri - Universitat de Barcelona - CINAF ${ }^{1}$
}

\section{Resumen}

El propósito de este breve texto es mostrar la movilidad del pueblo guna (Panamá) en el pasado y el presente, así como sus planes de futuro a corto plazo. Con ello me propongo analizar cómo, a pesar del movimiento continuo -a veces deseado a veces impuesto-, las sociedades indígenas del continente americano han llegado a construir sus territorios ancestrales y han desarrollado nuevas formas de arraigo con el espacio.

\begin{abstract}
The purpose of this short paper is to reflect on the mobility of the Guna (Panama) in the past, the present and their plans for the future. To do that I will analyze how, in spite of continuous movement -sometimes desired sometimes imposed by outsiders-, indigenous societies of the Americas have constructed their ancestral territories and they have developed new ways of belonging to space.
\end{abstract}

Panamá es un país que alberga una gran diversidad cultural. Como consecuencia de su posición geoestratégica, la población panameña está constituida por descendientes de mestizos hispano-indígenas, esclavos africanos de la época colonial, trabajadores afro-antillanos de habla francesa o inglesa traídos por franceses y norteamericanos, chinos que llegaron a mediados del siglo XIX para la construcción del Ferrocarril Transístmico, indostanos, hebreos y gentes de todas las nacionalidades atraídas por las expectativas económico-comerciales que abría el canal. La conquista del istmo y estas posteriores oleadas migratorias han tenido una gran afectación sobre la movilidad de los pueblos originarios del país.

Tras siglos de luchas y desplazamientos, ocho grupos indígenas viven todavía hoy en Panamá. Según el último censo de población (2010) los indígenas panameños

\footnotetext{
${ }^{1}$ Enviar correspondencia a: Mònica Martínez Mauri, martinezmauri@ub.edu
} 


\section{perifèria}

Número 18(2), diciembre 2013

http://revistes.uab.cat/periferia

suman 417.559 personas (el $12,3 \%$ de la población censada). Los gunas ${ }^{2}$ son 80.526 y constituyen el segundo grupo indígena del país. A grandes rasgos, la comarca de Guna Yala se caracteriza por 400 islotes próximos a la costa atlántica panameña y cuenta con 38 islas pobladas, dos comunidades situadas en el continente y ocho en la franja costera. Ocupa el $3,1 \%$ de la superficie del territorio de Panamá.

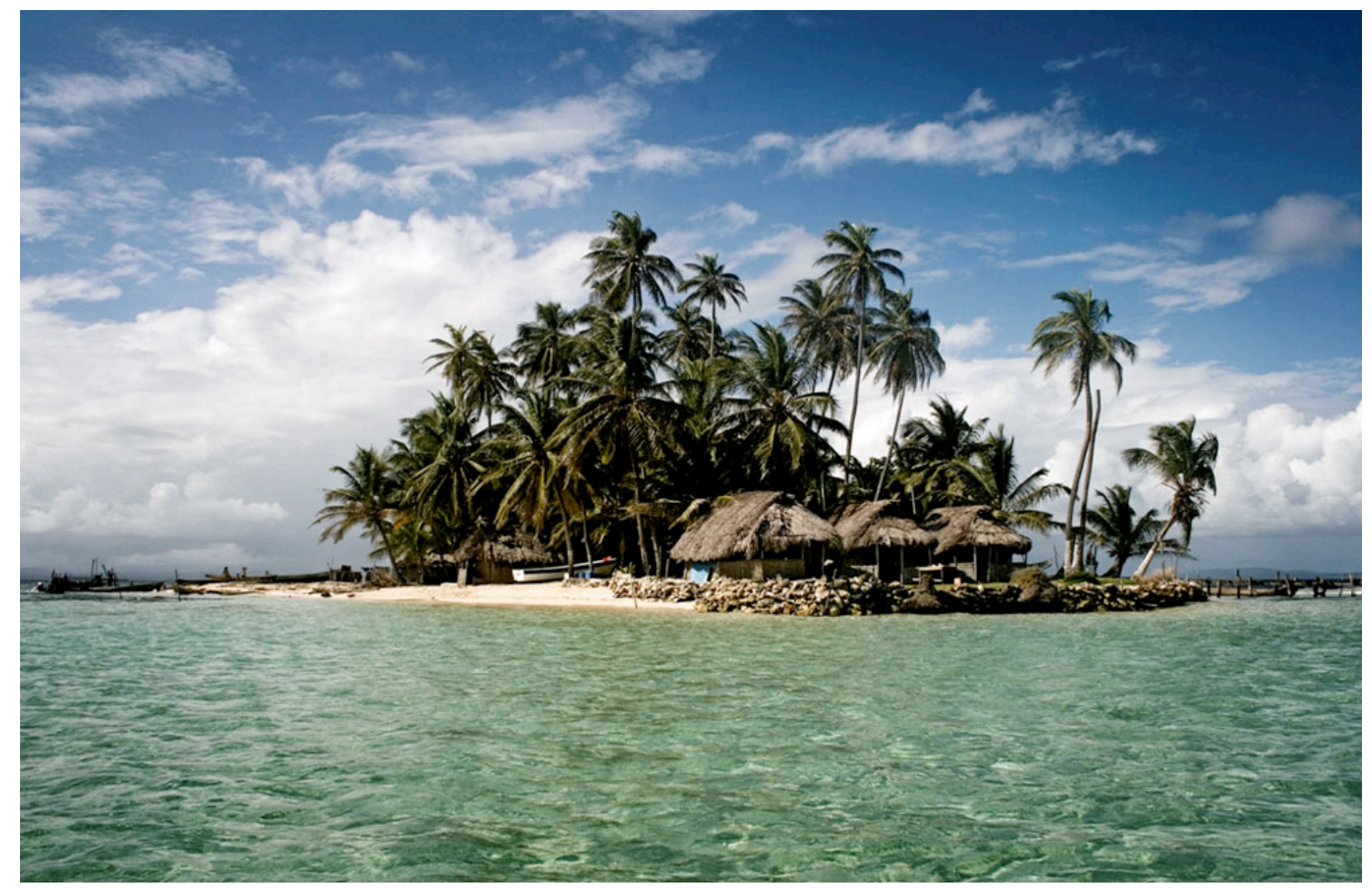

Aunque los gunas son internacionalmente conocidos por sus logros autonómicos en el plano territorial y gubernamental, las islas y las costas que hoy conforman su territorio sólo son una ínfima parte del espacio vivido por sus antepasados. Como muestra el testimonio de algunos ancianos, por ejemplo el argar José Davies, cuando vivían en la tierra firme las comunidades gunas cambiaban de emplazamiento cada 10 o 20 años. Todo parece indicar que no se sedentarizaron

2 En este texto sólo me referiré al pueblo guna (también denominado: kuna, tule o dule) que actualmente reside en las comarcas de Guna Yala, Madungandi, Wargandi, y en los principales centros urbanos de Panamá. 


\section{perifèria}

Número 18(2), diciembre 2013

http://revistes.uab.cat/periferia

por completo hasta que durante el siglo XIX fueron estableciendo su residencia en la costa de San Blas. La llegada al mar facilitó un mayor aprovechamiento de los recursos marinos, la intensificación del comercio y el aprovechamiento de nuevas tierras en el golfo de Mandinga. El abandono de los poblados del bosque por la ocupación de las islas comportó la construcción de una nueva territorialidad guna. Los límites del espacio vivido por los gunas hasta aquel entonces se transformaron dando lugar a un nuevo estilo de vida y sentimiento de locality (arraigo) (Appadurai, 1995). A continuación me propongo analizar brevemente algunos de los cambios que comportaron estos primeros traslados para conectarlos con las movilidades actuales.

\section{De la tierra firme al mar}

En la época colonial y gran parte del período republicano colombiano, cuando vivían en la tierra firme, la vida de sus antepasados estuvo marcada por enfrentamientos con los conquistadores castellanos, el éxito y el fracaso de las misiones jesuíticas y las epidemias de viruela en las zonas aledañas a los caudalosos ríos del Darién (la zona Este del país). En el siglo XVII los gunas aparecen establecidos en la costa atlántica. Los orígenes de esta ocupación no son claros todavía. Aunque los primeros etnógrafos que se encontraron con los gunas en el siglo $\mathrm{XX}$, los suecos Wassén $(1938,1949)$ y Nordenskiöld $(1928)$, creían que eran originarios del alto valle del Tuira, otros autores apuntan que llegaron ahí empujados por sus enemigos emberás tras la conquista y la fundación de los centros mineros de Toro (1573), Cáceres (1588) y Novita (1601) (Romoli, 1987: 50; Vargas, 1993: 41; Castillero Calvo, 1995: 263).

Hasta principios del siglo XIX no se produjo el movimiento gradual de la población de la costa hacia las islas (Stout, 1947; Howe, 1997: 89). Son varias las razones que parecen haber provocado este desplazamiento. La primera, seguramente no en importancia, obedece a motivos puramente económicos. Hacia 1870 aumentó la demanda de cocos desde Colombia y disminuyó la de productos tradicionalmente explotados por los gunas (principalmente el cacao y la tagua). Ante este nuevo 


\section{perifèria}

Número 18(2), diciembre 2013

http://revistes.uab.cat/periferia

panorama, los gunas se adaptaron a las nuevas exigencias del mercado exportando los cocos que plantaron en las islas. En poco tiempo, el nuevo cultivo se convirtió en el principal producto de exportación de la región y dado que el comercio era marítimo, adaptaron sus asentamientos a la nueva fuente de recursos (Stout, 1947; Tice, 1995; Howe, 1986, 1997: 89-90).

Otro factor que favoreció el movimiento hacia las islas fue el impacto de las epidemias y la malaria en la tierra firme (Howe, 1986; Tice, 1995). Los gunas no habían desarrollado remedios contra esta epidemia y estaban indefensos ante ella. Es muy probable que al valorar que los mosquitos y los otros animales que perturbaban su vida diaria -serpientes, cocodrilos o jaguares- no cruzaban el mar, decidieran abandonar el bosque.

Finalmente, la gran abundancia de recursos marinos, como tortugas, langostas y sábalo, también pudo influenciar en este cambio de emplazamiento de las comunidades. La pesca no era una actividad desconocida para los gunas, solían visitar la costa regularmente para proveerse de pescado. Seguramente el contacto con los escoceses y los bucaneros ingleses y franceses durante los siglos XVII y XVIII les proporcionaron los conocimientos y las herramientas básicas para hacer más efectivas sus capturas.

Aunque desconozcamos cuál de estos factores fue el determinante, lo que resulta inequívoco es que en pocas décadas la mayoría de las comunidades gunas abandonaron los cursos de los ríos y el contacto cotidiano con el bosque por el mar. Este cambio tuvo distintos efectos sobre su organización social. La división sexual del trabajo experimentó importantes transformaciones. Los hombres que hasta ese entonces se dedicaban a las actividades extractivas (caza y pesca), relevaron a las mujeres en el cuidado de las parcelas agrícolas. A partir del siglo XIX la agricultura se convirtió en una actividad eminentemente masculina. Dada la gran distancia que separaba las casas de los cultivos las mujeres fueron abandonando sus tareas 


\section{perifèria}

Número 18(2), diciembre 2013

http://revistes.uab.cat/periferia

agrícolas para dedicarse al comercio del coco y a la confección de las preciadas molas $^{3}$ (Howe, 1997: 90).

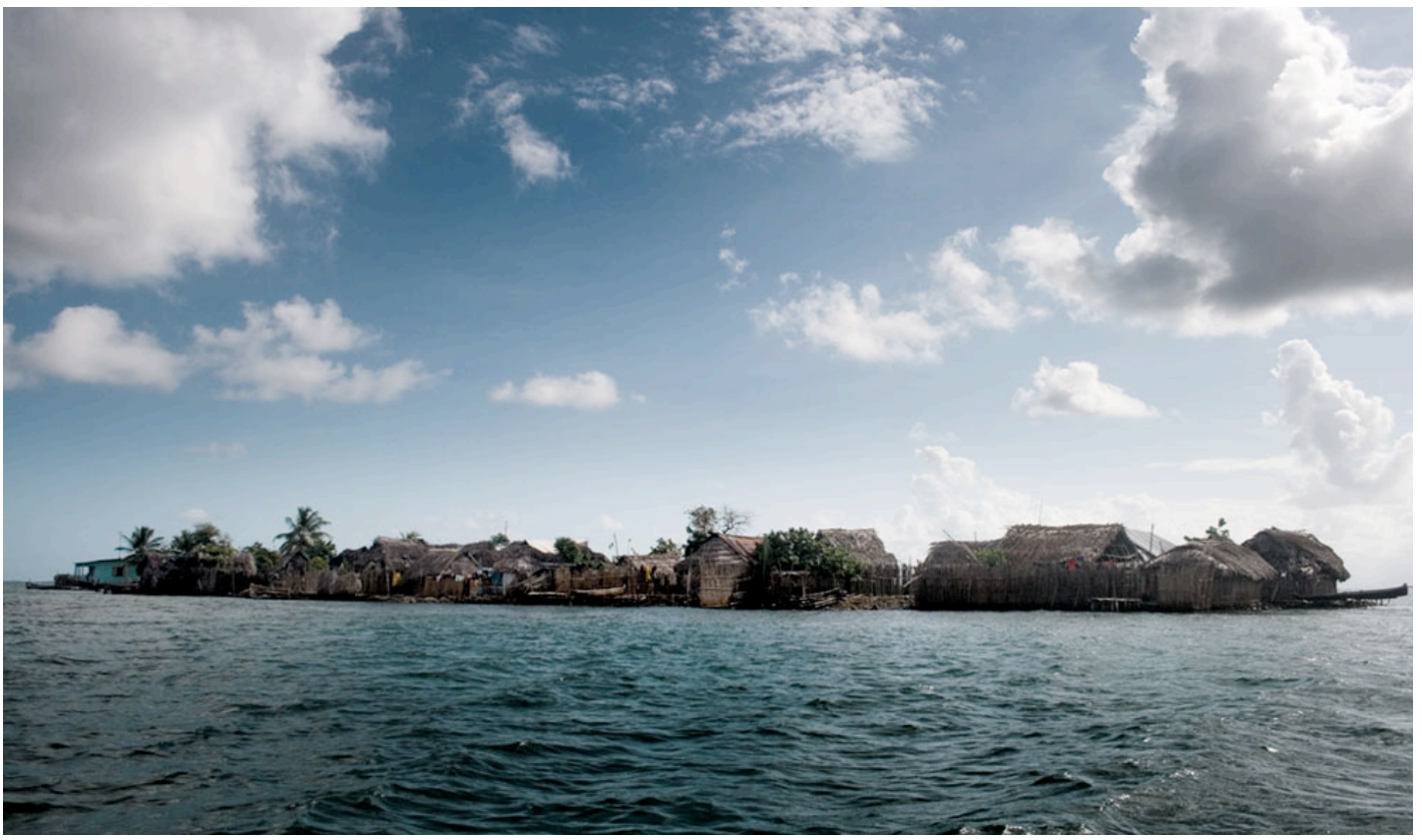

El traslado a las islas también tuvo efectos sobre las relaciones con el exterior. A diferencia de los ríos, las islas eran verdaderos lugares de paso. El contacto con el mar hizo posible que muchos jóvenes tuvieran la oportunidad de enrolarse como marineros en barcos británicos, americanos y canadienses. Así, además de aprender otras lenguas, muchos de ellos recorrieron grandes distancias sirviendo en estos barcos e hicieron participes de sus hazañas a los viejos de la comunidad. Cuando regresaban del extranjero, tenían que presentarse ante el pueblo en la casa del congreso para explicar sus experiencias y narrar lo que habían visto en el mundo exterior (Holloman, 1969: 420).

En 1871 los gunas firmaron un convenio con el Gobierno de Bogotá para proteger lo que consideraban que era su territorio ${ }^{4}$. Este documento resulta muy interesante

\footnotetext{
${ }^{3}$ Las molas son composiciones textiles elaboradas a partir de una técnica de aplicado que superpone diferentes capas de tejido conformando todo tipo de figuras.

${ }^{4}$ Cf. Morales, 1995; Convenio celebrado por la Secretaria de lo Interior i Relaciones con la tribu de los indígenas Tules moradora del Darién, 10 de enero de 1871, publicado en "Civilización de los Indios
} 


\section{perifèria}

Número 18(2), diciembre 2013

http://revistes.uab.cat/periferia

para ver la imagen que en el siglo XIX proyectaban los líderes indígenas del espacio que ocupaban. En este sentido, es pertinente señalar que los gunas se presentaron como los moradores de la costa de San Blas y manifestaron

"Que la tribu cultiva plátano, yuca, yame, batata, algodón, naranjo, mango, limonero, toronjo, piño, níspero, aguacate, mamei i chonta, i cria perros, patos, gallinas, gatos i cerdos. Que además de esto ejerce la pesca tanto en las aguas costaneras como en los muchos ríos que bañan la comarca, siendo la principal pesca la de tortuga de mar; i también ejerce la caza, la cual se hace ordinariamente con escopetas i algunas veces con arco i flecha, siendo los principales animales de caza los paujiles, las dantas i los pecaríes" ${ }^{5}$.

Es muy significativo que al hablar de las actividades de subsistencia que practicaban en su territorio, los delegados gunas hicieran referencia al mar y a sus recursos. Este hecho muestra que cuando los líderes indígenas negociaban con el gobierno partían de una concepción amplia del territorio. A partir del siglo XIX para ellos no sólo se trataba de una cuestión de tierras, sino que también se trataba de aguas y de recursos marinos.

En el siglo XIX, cuando las fronteras empiezan a definirse, las demandas territoriales se centran en las islas habitadas, los recursos agrícolas, forestales y marinos, es decir, en todo lo que hace posible la subsistencia de las aldeas. Esta es la razón por la que hasta la actualidad la noción guna de territorio -asociada a la idea de autonomía- no debe ser interpretada simplemente como "tierras" (parcelas agrícolas y bosques), sino que contempla las prácticas de subsistencia y reproducción, englobando así los distintos usos de la tierra y también del mar. La historia de su movilidad y su sedentarización en las islas explican porqué cuando los gunas hablan de territorio se refieren a aguas fluviales y marinas, parcelas

Tules", Imprenta de Medardo Rivas, 1871. Gracias a la gentileza de James Howe he podido disponer de ambos documentos.

${ }^{5}$ Convenio celebrado por la Secretaria de lo Interior $i$ Relaciones con la tribu de los indijenas Tules moradora del Darién: 4-5. 


\section{perifèria}

Número 18(2), diciembre 2013

http://revistes.uab.cat/periferia

agrícolas, bosques y recursos. Todos estos espacios forman parte del mundo vivido en los últimos siglos.

\section{Del mar a la ciudad}

Ya en el siglo $X X$ los gunas consiguieron que su territorio fuera reconocido $y$ protegido oficialmente como territorio indígena ${ }^{6}$. En 1938 con la creación de la comarca de San Blas, las tierras y las aguas de la actual comarca de Guna Yala fueron reconocidas como posesiones colectivas de los gunas que no podían ser enajenadas ni arrendadas. Más adelante, en 1996 se creó la comarca guna de Madungandi, y en el año 2000 la de Wargandi.

Pero este reconocimiento de la territorialidad indígena no significó el fin de la movilidad. La migración temporal o permanente de gunas a los centros urbanos y a las bananeras del Oeste del país ha sido uno de los factores que más ha marcado la sociedad guna durante el siglo XX. Al hablar de migraciones indígenas un primer punto a tener en cuenta es que no hubo una política unitaria del pueblo guna para favorecerlas o limitarlas. Algunos sailas (autoridades locales) creían que la migración acarreaba graves problemas a las familias y mermaba la producción de la región. Según el testimonio de algunas ancianas, cuando los hombres empezaron a migrar empezaron los problemas para las mujeres. Algunos se desentendían de sus familias, de manera que sus esposas e hijos no podían subsistir sin alguien que cultivara la tierra y practicara la pesca. La migración masculina trastocó el orden tradicional provocando la feminización de muchas comunidades. En cambio, para otros sailas, como por ejemplo Nele Kantule, la migración era considerada una oportunidad para el crecimiento de la comunidad, pues constituía una fuente indispensable de recursos. Los sueldos de los trabajadores gunas de la zona del canal o de las bananeras servían para adquirir bienes de consumo y ayudaban a las familias a educar a sus hijos. Por eso cuando los trabajos en la agricultura terminaban y llegaba el invierno Nele concedía tres meses de permiso a los

\footnotetext{
${ }^{6}$ Cf. Ley 2 de 16 de septiembre de 1938.
} 


\section{perifèria}

Número 18(2), diciembre 2013

http://revistes.uab.cat/periferia

comuneros de su comunidad, Ustupu, para ir a trabajar a Colón. La política proemigración de Nele Kantule lo llevó incluso a firmar un acuerdo en 1932 con el ejército norteamericano de la zona del canal para enviar trabajadores a las cocinas de las bases norteamericanas (Howe, 1995). Este pacto dio lugar a un sistema de migraciones organizadas hacia la zona del Canal, Ciudad de Panamá y las plantaciones de Banano de Changuinola.

Durante la segunda mitad del siglo XX los flujos migratorios se intensificaron. Muchos gunas se instalaron en las urbes para trabajar, estudiar o mantener un modo de vida no tradicional. En la periferia de los principales centros urbanos del país (Colón, Arraiján y Ciudad de Panamá) fundaron nueve barriadas: Dagar Gunyala, Abia Yala, Boo Yala, Kalu Mogir Yala, Nueva Esperanza, Kosguna, Guna Nega, Cativá y Ibeorgun. La mayoría de ellas se rigen todavía hoy por el sistema de organización política tradicional y mantienen relaciones con la comarca. En las ciudades las comunidades de Guna Yala también cuentan con centros o capítulos: una especie de "embajadas" y "puntos de reunión" que sirven para agrupar a los comuneros migrantes y gestionar los compromisos de la vida comunitaria desde la distancia.

Teniendo en cuenta los datos del último censo de población de la República de Panamá (2010) podemos sospesar la dimensión del fenómeno migratorio en la actualidad. En Panamá la población guna asciende a 80,526 personas, de las cuales 40.620 viven en la provincia de Panamá7. En la comarca de Guna Yala la población total es de 33.109 personas, de las cuales 30.308 se autoidentifican como gunas. Las cifras hablan por si solas: en estos momentos la población guna es más urbana que rural.

\footnotetext{
7 La comarca guna Madungandi con una población estimada en 3000 personas se encuentra en esta demarcación territorial.
} 


\section{perifèria}

Número 18(2), diciembre 2013

http://revistes.uab.cat/periferia

\section{¿Del mar a la tierra firme?}

En los últimos años un nuevo factor está determinando la movilidad del pueblo guna. Aunque las islas siguen siendo la residencia principal de los habitantes de Guna Yala, pronto podrían dejar de serlo. Las previsiones más pesimistas de algunos expertos señalan que el aumento del nivel del mar debido al cambio climático podría inundar muchas tierras bajas de Panamá, dañando zonas de cultivo en la costa y desplazando a centenares de personas de las comunidades costeras y de las pequeñas islas de la comarca (PNUD, 2002: 135). Otros investigadores apuntan que los islotes también corren el riesgo de desaparecer o transformarse por los efectos devastadores que podría tener un maremoto como el que ocurrió en 1882.

Por estos motivos, más la falta de espacio en las islas, a principios del año 2010, las comunidades de Ustupu, Goetupu, Ugupseni y Gardi Sugdub empiezan a hablar de la idea de establecerse en la tierra firme. Los debates son intensos, pues se plantean donde, cómo y cuando realizarlo sin contar con los recursos necesarios para asumir los costes de construcción de las nuevas aldeas. Estos proyectos de traslado son sumamente interesantes. Por un lado son un reto de planificación urbanística, por el otro abren un debate sobre la identidad guna, pues la cuestión central en este proceso es quién tiene derecho a un lote de tierra. Algunas personas de las comunidades afectadas sostienen que los comuneros que tengan deudas con el pueblo o estén casados con no gunas no tienen derecho a un lote y que los gunas de otras comunidades tampoco pueden poseer tierras en el nuevo poblado. Por el momento los traslados solo son proyectos, pero ya han desencadenado reflexiones que pueden marcar el futuro de la autonomía política guna.

Este proceso de traslado se produce paralelo a otro interesante desarrollo: la promoción del turismo en la región. Las normas comarcales estipulan con claridad que sólo los gunas pueden establecer hoteles y realizar actividades turísticas en las costas, playas e islas de la comarca. La secretaria de turismo del Congreso General verifica la fuente de las inversiones destinadas a la construcción de instalaciones turísticas para evitar la entrada de capital extranjero. Este nuevo boom turístico ha provocado que algunos gunas urbanos vuelvan a la comarca con la intención de 


\section{perifèria}

Número 18(2), diciembre 2013

http://revistes.uab.cat/periferia

invertir sus ahorros en este negocio. En algunos casos estas inversiones han sido posibles, pero en otros la falta de relación con la comunidad o las dificultades por llegar a un acuerdo con todos los propietarios de una isla ha frenado las pretensiones de los migrantes.

Después de este breve repaso de las formas de movilidad guna en el pasado y en el presente, entre la tierra firme, los centros urbanos y las islas, constatamos que a pesar de que los límites del territorio guna están bien definidos y consolidados, los gunas continúan moviéndose dentro y fuera de su comarca reconstruyendo el espacio comunitario sin perder por ende su arraigo con el lugar. A pesar de las presiones externas por explotar los recursos de su territorio y la necesidad de migrar para acceder a determinados bienes de consumo o servicios, su nega (hogar) les sigue perteneciendo y esperando.

\section{Bibliografía}

Appadurai, Arjun (1995). "The production of locality" en Counterworks: Managing the diversity of knowledge. Londres y Nueva York: Routledge, pp. 204-225.

Castillero Calvo, Alfredo (1995). Conquista, evangelización y resistencia: ¿Triunfo o fracaso de la política indigenista?. Panamá: Instituto Nacional de Cultura.

Holloman, Regina (1969). Developmental change in San Blas. Ph. Disseration. Northwestern University.

Howe, James (1986). The Kuna Gathering: Contemporary Village Politics in Panama. Austin: University of Texas Press.

Howe, James (1995). "La lucha por la tierra en la costa de San Blas (Panamá), 1900-1930". Mesoamerica, no 29, pp. 57-76. 


\section{perifèria}

Número 18(2), diciembre 2013

http://revistes.uab.cat/periferia

Howe, James (1997). "The Kuna and the World: Five Centuries of Struggle" The art of being kuna. Los Angeles: Ucla Fowler Museum of Cultural history, pp. $85-102$. Morales, Jorge (1995). "El convenio de 1870 entre los cunas y el estado colombiano: sentido de una acción de resistencia". Revista Colombiana de Antropología, no XXXII, pp. 187-196.

Nordenskiöld, Erland (1928). "An Historical and Ethnological Survey of the cuna Indians". Comparative Ethnographical Studies, no 10, Gotemburgo.

PNUD (2002). Informe Nacional de Desarrollo Humano. Panamá 2002. El compromiso con el desarrollo humano: Un desafío nacional. Panamá: PNUD.

Romoli, Kathlen (1987). Los de la lengua Cueva. Las tribus del Istmo Oriental al Tiempo de la Conquista Española. Bogotá: ICAN.

Stout, David (1947). San Blas Cuna Acculturation: An Introduction. Nueva York: Viking Fund.

Tice, Karen E. (1995). Kuna Crafts, Gender, and the Global Economy. Austin: University of Texas Press.

Vargas, Patricia (1993). Los Embera y los Cuna: Impacto y reacción ante la ocupación española. Siglos XVI y XVII. Bogotá: CEREC, Instituto Colombiano de Antropologia.

Wassén, Henry (1938). "Original documents from the Cuna Indians of San Blas, Panamá". Etnologiska Studier, no 6, pp. 1-178.

Wassén, Henry (1949). "Contributions to Cuna Ethnography". Etnologiska Studier, n०16, Gotemburgo. 